\title{
GESTÃO ESCOLAR DEMOCRÁTICA: UM OLHAR SOBRE AS ESCOLAS DO CAMPO DO MUNICÍPIO DE ITABUNA - BA
}

\author{
DEMOCRATIC SCHOOL MANAGEMENT: A LOOK AT THE FIELD SCHOOLS OF \\ THE MUNICIPALITY OF ITABUNA-BA
}

\author{
V. P. dos SANTOS e A. R dos SANTOS ${ }^{1}$ \\ 1 Universidade Estadual de Santa Cruz, Programa de Pós-Graduação em Educação - PPGE. \\ Ilhéus/Bahia/Brasil.
}

\section{ART I C LE INFO}

Received 2018-08-15

Accepted 2018-10-15

Available online 2018-10-31

*Autor correspondente:

E-mail:prof.valeriah@gmail.com
Palavras-chave: Democracia. Educação do Campo. Gestão escolar democrática.

Keywords: Democracy. Field Education. Democratic school management.

RESUMO: O presente artigo visa fazer uma discussão tomando como ponto de apoio uma pesquisa qualiquantitativa que teve como objetivo investigar como se dá a Gestão Democrática nas escolas do Campo do Município de Itabuna - BA, como uma ferramenta de transformação social no contexto do sistema capitalista. Os instrumentos para coleta de dados foram revisão bibliográfica e aplicação de questionários, o referencial teórico traz como suporte o materialismo histórico dialético. Legalmente, fundamentamo-nos documentos oficiais nacionais, Constituição federal (1988), Lei de Diretrizes e Bases (1996) e as Diretrizes Operacionais para a Educação Básica das Escolas do Campo (2002), no intuito de melhor entender como se efetiva a gestão escolar democrática no contexto campesino. No debate da democracia sob o viés socialista foram utilizados alguns autores, a exemplo de Coutinho (1979), Hora (2007) e Wood (2006), além de outros. Os resultados da pesquisa mostram que apesar de muitas vezes afirmar-se que existe gestão democrática nas escolas do campo, as práticas não são verdadeiramente democráticas, uma vez que não envolve todos os sujeitos da comunidade escolar.

ABSTRACT: The present article aims to make a discussion based on a qualitative and quantitative research whose objective was to investigate how the Democratic Management in Field schools of the Municipality of Itabuna - BA, as a tool of social transformation in the context of the capitalist system. The instruments for data collection were bibliographic review and application of questionnaires, and the theoretical reference brings as support, the dialectical historical materialism. Legally, we are based on the official national documents, the Federal Constitution (1988), the Guidelines and Bases Law (1996) and the Operational Guidelines for Basic Education of the Field Schools (2002), in order to better understand how democratic school management is effective in the peasant context. In the debate of democracy under the socialist bias, some authors were used, like Coutinho (1979), Hora (2007) and Wood (2006), as well as others. The results of the research show that although it is often affirmed that there is democratic management in the rural schools, the practices are not truly democratic, since it does not involve all the subjects of the school community. 


\section{INTRODUÇÃO}

Este artigo visa discutir dados acerca da Gestão Democrática nas Escolas do Campo, tomando como referência a análise de uma pesquisa realizada sobre o impacto do Plano de Ações Articuladas (PAR) nas escolas do campo de três municípios da Bahia, a saber: Vitória da Conquista, Ilhéus e Itabuna1. Entretanto, elencamos como recorte espacial para este texto, tão somente o município de Itabuna-Ba.

O município de Itabuna fica localizado no Sul do estado da Bahia. Possui uma área total de $432,244 \mathrm{~km}^{2}$ e está localizada a 426 quilômetros da capital da Bahia, estando em torno de 333 quilômetros de distância dessa cidade via ferryboat. É a quinta cidade mais populosa da Bahia com uma população estimada em 2016, em 220.386 habitantes (IBGE, 2010).

Compreendendo gestão democrática como uma ferramenta de transformação social, entende-se que a mesma se faz distante do ideário capitalista, uma vez que este visa manter a desigualdade para concentrar nas mãos de poucos os benefícios de classe. Para Santos,

A gestão participativa e democrática, na ótica da classe trabalhadora, não deve buscar seguir o propósito neoliberal, mas sim, adequar os seus objetivos de forma que beneficie os trabalhadores. Todos participam da tomada de decisões e, dividindo tarefas, e têm como ponto central a relação orgânica entre direção e todos os envolvidos na instituição (2014, p.201).

A gestão escolar democrática deve contar com a participação de todos que fazem parte da comunidade escolar, afastando-se dos ideais neoliberais de individualismo e tomando para si o ideal político de mudança de realidade para que sejam repensadas as práticas autoritárias presentes ainda hoje nas escolas.

O recorte desse trabalho foi feito com um olhar para a educação do campo, por compreendê-la como um espaço de lutas e participação dos movimentos sociais, todavia, percebe-se também que a realidade da maioria das escolas do campo do nosso país, tem a gestão democrática como algo distante por todo o processo de esquecimento que esse público teve ao longo dos anos. Nesse sentido, optamos por fazer uma breve contextualização sobre a democracia e a gestão democrática. E em seguida, apresentamos os dados da pesquisa.

\footnotetext{
${ }^{1}$ Pesquisa realizada com financiamento do CNPq e da Fundação de Amparo à Pesquisa da Bahia (FAPESB), pelo Grupo de Estudos Movimentos Sociais, Diversidade e Educação do Campo (GEPEMDEC), inserido no Centro de Estudos e Pesquisas em Educação e Ciências Humanas - CEPECH do Departamento de Ciências da Educação - DCIE da UESC - BA.
} 


\section{DEMOCRACIA NA SOCIEDADE ATUAL}

Defendido e expandido etimologicamente na sua tradução literal, "democracia" tem origem do grego, e vem de Demokratia. O referido termo possui em sua base duas palavras gregas: Demos que significa "povo, distrito"; e Kratos, que expressa "Domínio, poder" - o que nos traz o significado de "poder do povo" ou "governo do povo", segundo o dicionário online de língua portuguesa (2017). O significado ajudou na sua propagação no campo político a partir do século XX como uma espécie de salvação, principalmente em países com governos ditatoriais e ou de participação popular limitada.

Embora sempre remonte à experiência fundadora dos gregos com participação popular, respeitando a escolha da maioria da população, é necessário lembrar de que a cidade para os gregos consistia no "agrupamento ideal dos seres humanos" (Chevalier, 1982, p. 21), desde que não fugisse a esse padrão ideal: mesma nacionalidade, livres, homens, ou seja, pertencessem a um grupo privilegiado, logo, um governo democrático não era vivido por todos, uma vez que nem todos eram considerados cidadãos.

No século $X X$, após a pressão dos movimentos sociais que vinham ganhando notoriedade desde o século XVIII, e das ideias do filósofo iluminista Jean-Jacques Rousseau na obra "O contrato social", na qual introduzia importantes ideias acerca da democracia, embora num contexto de valorização do capitalismo emergente, a burguesia toma para si a ideia de democracia e essa passa ser uma das "bandeiras" do pensamento liberal, de uma forma modificada para que servisse aos interesses do capital. Neste sentido, Santos (2014, p.177) afirma "[...] a democracia plena não existe no sistema capitalista, pois a presença do Estado nesse contexto tem como objetivo garantir a exploração do homem pelo homem".

Para que se compreenda melhor a democracia no século XXI, é preciso inserir-se no contexto político atual. Vivemos em uma sociedade capitalista e como tal, temos uma democracia voltada aos padrões capitalistas de governo. Isso porque forma de governo e de economia estão intimamente relacionados. Neste sentido, Engels afirma que

Como o Estado nasceu da necessidade de conter o antagonismo das classes, e como, ao mesmo tempo, nasceu em meio ao conflito delas, é, por regra geral, o Estado da classe economicamente dominante, classe que por intermédio dele, se converte também em classe politicamente dominante e adquire novos meios para a repressão e exploração da classe oprimida. Assim, o Estado antigo foi, sobretudo, o Estado dos senhores de escravos para manter os escravos subjugados; o Estado feudal foi o órgão de que se valeu a nobreza para manter a sujeição dos servos e camponeses dependentes; e o moderno Estado representativo é o instrumento de que se serve o capital para explorar o trabalho assalariado (ENGELS, 2002, p. 137).

A ideia de democracia (representativa), restringe-se, muitas vezes, ao direito à representação através do voto. A democracia, segundo o olhar marxista é um campo de luta dos movimentos sociais por representatividade e participação efetiva voltada à 
transformação social. Nesse sentido, Carnoy observa que "[...] foram sempre os movimentos dos trabalhadores que tiveram que lutar contra a tendência da democracia representativa de rejeitar a participação social [...] Foi a classe trabalhadora que deu conteúdo democrático às instituições liberais representativas." (CARNOY, 1988, p. 210).

Compreender a democracia fora do sistema capitalista é ideal para que haja a transformação social, para, tal como afirma Bordenave (1994, p.22) possamos ter um processo onde se possa "fazer parte, tomar parte, ter parte" das decisões e responsabilidades, sucessos, insucessos. Não é possível pensar a democracia substantiva num cenário de individualismo, na estreiteza e desigualdades do sistema capitalista.

\section{GESTÃO ESCOLAR DEMOCRÁTICA}

Muitas vezes a participação popular ou mesmo a participação de outros funcionários na tomada de decisões da escola está exclusivamente no "fazer parte da escola" e das reuniões como um mero espectador. O processo de gestão democrática escolar conforme preconiza os documentos oficiais está intimamente voltado à participação e a ser sujeito agente das ações desenvolvidas no ambiente escolar, conforme destacaremos mais adiante.

No âmbito escolar, a gestão democrática passa a compor os documentos oficiais do Brasil a partir da Constituição Federal de 1988, a qual simbolizou um marco quando em seu artigo $1^{\circ}$ institui o "Estado Democrático de Direito" e, com isso, a ideia de participação na esfera pública a todos os cidadãos, além da democratização dos direitos sociais, e nesse contexto se insere o direito à educação. Posteriormente, a promulgação da Lei de Diretrizes e Bases da Educação Nacional, no 9.394/96 LDB reafirma o princípio da gestão democrática no seu Art. 14, quando dispõe que

Art. 14. Os sistemas de ensino definirão as normas de gestão democrática do ensino público na educação básica, de acordo com as suas peculiaridades e conforme os seguintes princípios: I - participação dos profissionais da educação na elaboração do projeto político-pedagógico da escola; II - participação das comunidades escolar e local em Conselhos Escolares ou equivalentes (BRASIL, 1996).

Neste sentido, podemos fazer os seguintes questionamentos: em que consiste realmente a gestão democrática? Como os sujeitos da escola estão trabalhando para exercê-la de uma forma a contrapor o sistema capitalista e a influenciar na emancipação humana?

Antes de firmar mais profundamente uma discussão acerca de gestão democrática no ambiente escolar, faz-se necessário compreender a sociedade em que vivemos e como nela é possível reverter a formação alienante dos sujeitos. Neste sentido, Wood (2006, p.7- 
8) corrobora com a explicitação de como a o capitalismo limita o processo democrático quando diz que ele

[...] é incompatível não apenas no caráter óbvio de que o capitalismo representa o governo de classe pelo capital, mas também, no sentido de que o capitalismo limita o poder do povo entendido no estrito significado político. Não existe um capitalismo governado pelo poder popular, não há capitalismo em que a vontade do povo tenha precedência sobre os imperativos do lucro e da acumulação, não há capitalismo em que as exigências de maximização dos lucros não definam as condições mais básicas da vida.

A preocupação do capitalismo é com a manutenção e do poder e do capital, pois nesse sistema, o poder do povo é limitado uma vez que o mesmo baseia-se na exploração da força de trabalho e na desumanização do homem, se o mesmo obtivesse efetiva participação política e social de maneira libertadora, modificaria a situação de homem (agora explorado e alienado).

Com o recente processo de democratização escolar, são recentes também as práticas democráticas dentro da escola. A formação de intelectuais que correspondam aos interesses da classe dominada precisa ser trabalhada dentro da escola que continua a contribuir para a manutenção da classe dominante. Para Paro (2012, p. 126), "a classe revolucionária impedirá essa recomposição de forças dos grupos dominantes se for capaz de remeter-se decisivamente em direção à transformação social, criando um novo sistema hegemônico sob sua direção".

A escola pode, através do enfrentamento ao sistema hegemônico vigente, proporcionar práticas de valorização humana em detrimento da valorização apenas para o sistema de produção, como se faz no capitalismo.

O grande desafio está em fazer essa transformação social acontecer, neste sentido, Mészáros (2004) explicita que a educação formal não é a força ideologicamente primária que cimenta o sistema capitalista; nem é capaz de, por si só, fornecer uma alternativa emancipadora radical, por outro lado, a afirmação de uma formação humana de nenhuma maneira pretende destituir o papel da educação formal no contexto das relações sociais.

Não é apenas com a gestão democrática do ambiente escolar que a escola faz de seu espaço um lugar emancipador, isso compreende uma amplitude de fatores como pertencimento social, reconhecimento de classes e de lutas constantes, ambiente propício à uma aprendizagem rica, com professores intelectuais orgânicos a serviço da luta dos trabalhadores.

Na gestão democrática, a gestão é compartilhada, fruto de decisões pensadas em conjunto, não compreende apenas um gestor, mas sim as várias partes constituintes do funcionamento do trabalho, as quais devem estar associadas para a construção de um produto coletivo.

Hora (2007, p.50) compreende que 
"[...] a escola, como organização social, também pretende ser um espaço democrático, de modo que os educadores profissionais, os alunos, os pais, os ativistas comunitários e outros cidadãos do contexto social imediato tenham o direito de estarem bem informados e de terem uma participação crítica na criação e de execução das políticas e dos programas escolares".

Associado a isso, a autora (Ibidem, 2007, p. 50), elenca mais dois pontos para garantir que uma escola seja verdadeiramente democrática:

1 - A criação de estruturas e processos democráticos pelos quais a vida escolar realiza-se, representada pela participação geral nas questões administrativas e políticas, pelo atendimento a preocupações, expectativas e interesses coletivos e pela posição firme contra o racismo, a injustiça, o poder centralizado, a pobreza e desigualdade presentes na escola e na sociedade.

2 - O desenvolvimento de um currículo que ofereça experiências democráticas aos estudantes, cujas características estejam na multiplicidade das informações; no direito de se expressar e de se fazer ouvir na construção social do conhecimento; na formação de leitores críticos da realidade; no processo criativo de ampliação dos valores democráticos e experiências de aprendizado organizado em torno da problematização e do questionamento.

Assim, para uma transformação social a escola deveria trabalhar para a consciência crítica, para a participação efetiva dos sujeitos, não como um órgão centralizador, onde não há uma reflexão acerca dos mecanismos de ensino-aprendizagem, troca de experiências, participação política, horizontalidade de poderes entre outros componentes necessários para uma escola menos alienadora e mais eficaz no processo de transformação social.

Sob essa ótica, Coutinho (1979, p. 40) contribui em relação ao entendimento sobre a democracia socialista, pois é uma democracia pluralista de massas, uma democracia organizada, na qual:

[...] a hegemonia deve caber ao conjunto dos trabalhadores representados através da pluralidade dos seus organismos (partidos, sindicatos, comitês de empresa, comunidades de base, [comunidade escolar] etc.). Se o [neo] liberalismo afirma teoricamente o pluralismo e mistifica/oculta a hegemonia, se 0 totalitarismo absolutiza a dominação e reprime o pluralismo, a democracia de massas funda sua especificidade na articulação do pluralismo com a hegemonia, na luta pela unidade na diversidade dos sujeitos políticos coletivos autônomos (grifos do autor).

A escola, assim como os demais espaços da sociedade civil, através da criação de ideais democráticos deveria exercer um papel incentivador nas lutas e estimular a participação da comunidade, dos pais, dos alunos, criar e estimular o reconhecimento verdadeiro do que é democracia além do viés capitalista que cerceia o poder nas mãos de poucos, que disfarça a sua crueldade através dos mecanismos de persuasão fazendo com que se creia na meritocracia. Para Mészáros (2005, p. 45),

"[...] esperar da sociedade mercantilizada uma sanção ativa - ou mesmo mera tolerância - de um mandato que estimule as instituições de educação formal a abraçar plenamente a grande tarefa histórica do nosso tempo, ou 
seja, a tarefa de romper com a lógica do capital no interesse da sobrevivência humana, seria um milagre monumental. É por isso que, também no âmbito educacional, as soluções "não podem ser formais, elas devem ser essenciais". Em outras palavras, elas devem abraçar a totalidade das práticas educacionais da sociedade estabelecida."

Não é uma tarefa simples, no sistema capitalista, instituir uma educação transformadora, mas ela é objeto de luta daqueles que acreditam na constituição de uma sociedade mais justa. Através da Constituição Federal de 1988 e da Lei de Diretrizes e Bases da Educação Nacional, no 9.394/96, é dada a parte legal para uma escola participativa e que valorize as contribuições de todos os sujeitos, embora seja nos marcos da sociedade capitalista. Porém, podemos contrariar a ótica individual, ainda que encontremos os entraves na política neoliberal na qual estão subjacentes as políticas educacionais do nosso país.

\section{GESTÃO DEMOCRÁTICA NA EDUCAÇÃO DO CAMPO}

A Educação do Campo tem sua gênese no Brasil, em 1997, no I Encontro Nacional de Educação na Reforma Agrária - ENERA, e se consolidou a partir das lutas dos movimentos sociais do campo, cujo objetivo é a luta contra a hegemonia capitalista do agronegócio. A luta por uma Educação do Campo reconhece "o povo do campo como sujeitos das ações e não apenas sujeitos às ações de educação, de desenvolvimento, e assumem como sua tarefa educativa específica a de ajudar às pessoas e às organizações sociais do campo para que se vejam e se construam como sujeitos, também de sua educação" (CALDART, 2004, p. 151- 152, grifos da autora).

Nesse processo de luta, a educação do Campo vem alcançando maior notoriedade desde a Constituição Federal de 1988 (ainda que tratada como 'educação rural') quando inclui, no artigo 205, que "a educação é direito de todos e dever do Estado e da família", contudo, garantir a universalização, apesar de um passo importante, não abrange a qualidade que era uma das principais preocupações dos movimentos em prol da Educação do Campo. Com a Lei de Diretrizes e Bases da Educação Nacional no 9.394/96, há a ampliação das especificidades da Educação do Campo nos artigos 23, 26 e 28, e a mesma passa a ser modalidade de ensino. Ressalta-se, sobretudo o artigo 28 que diz:

$\mathrm{Na}$ oferta de educação básica para a população rural, os sistemas de ensino promoverão as adaptações necessárias à sua adequação às peculiaridades da vida rural e de cada região, especialmente:

I - conteúdos curriculares e metodologias apropriadas às reais necessidades e interesses dos alunos da zona rural;

II - organização escolar própria, incluindo adequação do calendário escolar às fases do ciclo agrícola e às condições climáticas;

III - adequação à natureza do trabalho na zona rural.

Parágrafo único. O fechamento de escolas do campo, indígenas e quilombolas será precedido de manifestação do órgão normativo do respectivo sistema de ensino, que considerará a justificativa apresentada 
pela Secretaria de Educação, a análise do diagnóstico do impacto da ação e a manifestação da comunidade escolar (BRASIL, 1996).

A organização e adequação da lei às especificidades do campo são conquistas do processo de luta dos movimentos sociais campesinos por uma educação de qualidade, pois através dessas formas de mobilização surgiram outros documentos complementares à LDB, buscando efetivar a garantia dos direitos negados por tanto tempo. Em 2001, as Diretrizes Operacionais para a Educação Básica nas escolas do Campo são aprovadas; em 2006, pelo parecer CNE/CEB № 1, de 02 fevereiro é homologado o documento que trata da aplicação de dias letivos para a Pedagogia de alternância; em 2008, pela Resolução no 2, de 28 de abril, são estabelecidas as diretrizes complementares, normas e princípios para o desenvolvimento de políticas públicas de atendimento da Educação Básica do Campo; em 2010, o Decreto $n^{0}$ 7.352, de 4 de novembro que Dispõe sobre a política de educação do campo e o Programa Nacional de Educação na Reforma Agrária - PRONERA.

Esses documentos expressam resultados de luta por uma educação diferenciada para os povos do campo, com respeito à sua forma de vida, às diferenças dos povos que nele vivem e produzem o bem viver. Por isso, a luta é por uma educação no e do Campo. No: o povo tem direito a ser educado no lugar onde vive; Do: o povo tem direito a uma educação resultante das reivindicações dos processos formativos, vinculada à sua cultura e às suas necessidades humanas e sociais (CALDART, 2004).

Esse projeto gestacional de se ter uma educação voltada às diferenças de tempos e espaços do campo apresenta-se de maneira tímida quando se refere à gestão democrática. A mesma é apoiada no artigo 14 da Lei de Diretrizes e Bases da Educação Nacional, 9.394/96, e é ampliada nas Diretrizes Operacionais para a Educação Básica nas Escolas do Campo, em que, nos artigos 10 e 11 asseguram:

Art. 10. O projeto institucional das escolas do campo, considerado o estabelecido no artigo 14 da LDB, garantirá a gestão democrática, constituindo mecanismos que possibilitem estabelecer relações entre a escola, a comunidade local, os movimentos sociais, os órgãos normativos do sistema de ensino e os demais setores da sociedade.

Art. 11. Os mecanismos de gestão democrática, tendo como perspectiva o exercício do poder nos termos do disposto no parágrafo $1^{\circ}$ do artigo $1^{\circ}$ da Carta Magna, contribuirão diretamente:

I - para a consolidação da autonomia das escolas e o fortalecimento dos conselhos que propugnam por um projeto de desenvolvimento que torne possível à população do campo viver com dignidade;

II - para a abordagem solidária e coletiva dos problemas do campo, estimulando a autogestão no processo de elaboração, desenvolvimento e avaliação das propostas pedagógicas das instituições de ensino (BRASIL, 2002).

Aqui também há de levar-se em consideração o caráter específico da educação do campo. Pelas localidades onde se encontram as comunidades do campo ser menores, há uma probabilidade grande de o laço comunitário ser maior. Assim, segundo Gracindo (2006, p.46), 
As características próprias da Escola do Campo propiciam uma maior convivência com as formas organizativas da vida produtiva, cultural, religiosa e política do campo. Com isso, a gestão democrática inclui a possibilidade do professor participar das reuniões comunitárias e abrigar, na escola, assembleias gerais da comunidade. Desta forma, a escola pode se tornar um espaço para encontros da comunidade e dos movimentos sociais como uma das formas de estímulo à participação de todos na vida escolar.

Todavia, esse ambiente propício a uma gestão democrática esbarra nos entraves burocráticos, aspectos políticos, despreparo do pessoal para abrir a escola à comunidade. Muitas das escolas do campo são de unidocentes, multisseriadas, características que devem ser levadas em conta no processo de articulação da gestão democrática, as diferenças entre campo e sede devem ser consideradas em todo o processo constitutivo.

\section{ASPECTOS METODOLÓGICOS DA PESQUISA}

A nossa pesquisa configura-se como quali-quantitaviva caracterizada pela descrição, compreensão e interpretação de fatos e fenômenos. Segundo Minayo (2011, p.22) "a abordagem qualitativa aprofunda-se no mundo dos significados das ações e relações humanas, um lado não perceptível e não captável em equações, médias e estatísticas" e quantitativas, pois a presente pesquisa se debruçará sobre os resultados numéricos, visando quantificar para atribuir significado ao que foi pesquisado. Para a autora, o conjunto de dados quantitativos e qualitativos não se opõem. Ao contrário, se complementam, pois a realidade abrangida por eles interage dinamicamente, excluindo qualquer dicotomia.

Os resultados aqui apresentados fazem parte de uma pesquisa sobre o impacto das políticas educacionais do PAR em escolas do campo de municípios da Bahia. Porém, recortamos apenas alguns aspectos evidenciados sobre a gestão em escolas do campo, no município de Itabuna. Para coleta dos dados estabelecemos um recorte temporal o período entre 2010 e 2017. Os números sobre as escolas do campo no referido município podem ser observados na Tabela 1.

Tabela 1 - Quantidade de escolas e alunos da rede municipal de ensino de Itabuna

\begin{tabular}{ccccccc}
\hline \multirow{2}{*}{ ANO } & \multicolumn{2}{c}{ ESCOLAS } & \multicolumn{3}{c}{ ALUNOS } \\
& Campo & Cidade & TOTAL & Campo & Cidade & TOTAL \\
\hline $\mathbf{2 0 1 3}$ & 31 & 78 & 109 & 824 & 19.541 & 20.365 \\
$\mathbf{2 0 1 4}$ & 25 & 78 & 103 & 668 & 18.747 & 19.415 \\
$\mathbf{2 0 1 5}$ & 25 & 75 & 100 & 669 & 18.040 & 18.709 \\
$\mathbf{2 0 1 6}$ & 24 & 73 & 97 & 560 & 16.752 & 17312 \\
\hline \multicolumn{7}{c}{ Fonte: SANTOS; OLIVEIRA; CARDOSO (2017). }
\end{tabular}

Os dados da Tabela 01 apontam para uma realidade que vem se tornando constante nos municípios brasileiros e os municípios pesquisados não estão distantes desta realidade, 
uma vez que desde 2013 as escolas do campo vêm sendo fechadas. Em Itabuna, das trinta e uma (31) escolas do campo, sete (7) foram fechadas, passando para vinte e cinco (25) escolas em 2014 e 2015. Em 2016, mais uma escola foi fechada e agora temos apenas vinte e quatro (24) escolas. Esse fenômeno também tem ocorrido nas escolas da cidade, mas não na mesma proporção, conforme dados apresentados.

Inicialmente, realizamos uma revisão de literatura e documental das políticas públicas que estão sendo implementadas nos municípios investigados, observando quais os objetivos, os pressupostos teóricos que as fundamentam, e como estão estruturadas nas instâncias Federal, Estadual e Municipal. Para verificar o resultado obtido com a implementação das políticas educacionais do PAR, tanto do ponto de vista das secretarias municipais como na visão dos sujeitos da comunidade escolar, foram realizadas entrevistas semiestruturadas com diretores, coordenadores e professores. Aplicamos, também, questionários com os professores dos municípios investigados, e no caso de Itabuna, a nossa pesquisa consistiu na aplicação de questionários de perguntas fechadas, no ano de 2016, a 21 professores da Educação do Campo, que depois tiveram suas respostas agrupadas e distribuídas em gráficos. Salientamos que escolhemos apenas os dados das questões destes questionários que versam sobre a gestão escolar para apresentar nesse artigo.

A análise dos dados contou com o suporte metodológico do materialismo histórico dialético, porque compreendemos que através dele pode-se ter uma visão mais fidedigna da realidade, buscando compreender o modo humano de produção da existência social.

\section{Resultados da pesquisa}

A partir dos dados coletados, tendo como referência, apenas alguns aspectos demonstrados nos questionários no tocante à gestão escolar, apresentamos os elementos e discussões que se seguem. A primeira indagação usada aqui se refere à forma de escolha da gestão da escola, cujo questionamento obteve o seguinte resultado: por eleição: 0 , indicada pela SMED: 12, Por concurso: 5, Não responderam: 4.

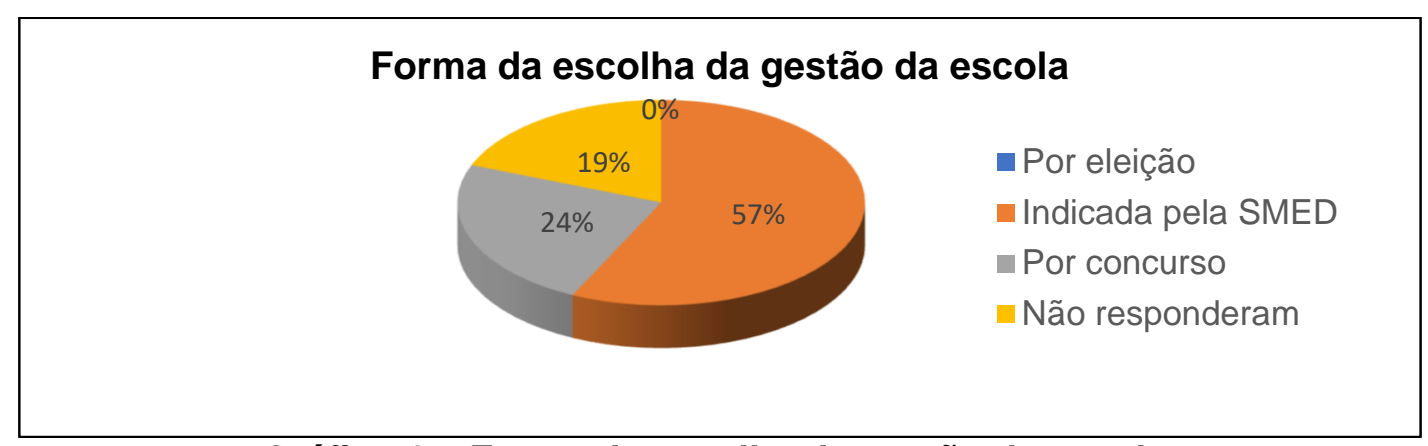

Gráfico 1 - Forma de escolha da gestão da escola.

Fonte: Dados elaborados pelas autoras a partir da pesquisa de campo (2016). 
Percebemos no Gráfico 1 que a forma predominante de escolha da gestão escolar no município pesquisado ainda é a indicação pela Secretaria Municipal de educação, uma vez que $57 \%$ dos sujeitos são indicados. Tal dado evidencia um descompasso frente ao que está posto na LDB n 9.394/96, pois ao ser indicado, os gestores nem sempre terão autonomia preconizada no texto legal, em seu Art. 15: "Os sistemas de ensino assegurarão às unidades escolares públicas de educação básica que os integram progressivos graus de autonomia pedagógica e administrativa e de gestão financeira, observadas as normas gerais de direito financeiro público" (BRASIL, 1996). As formas mais marcantes da autonomia na gestão escolar têm sido concretizadas por meio das eleições de diretores, criação de conselhos escolares e reuniões de pais.

Apesar de esses mecanismos representarem um avanço, eles têm se mostrado insuficientes para arranhar o controle do Estado sobre a educação. De fato, só a eleição não garante que os diretores pensem na qualidade do ensino do ponto de vista de classe. Paro (2001) enfatiza que a indicação traz consigo as marcas do clientelismo político, sendo por isso uma das mais criticadas, mesmo que esteja muito presente nos sistemas de ensino de algumas regiões brasileiras, esse resultado mostra que esse aspecto não conta com a participação popular, todavia isso não configura que a escola não possa ser democrática, apenas que o gestor é, na maioria das vezes, escolhido pela Secretaria de Educação.

Quando perguntados sobre como é a forma de gestão, a resposta foi a seguinte: Autoritária: 0; Democrática: 8; Democrática-participativa: 10; Não responderam: 3.

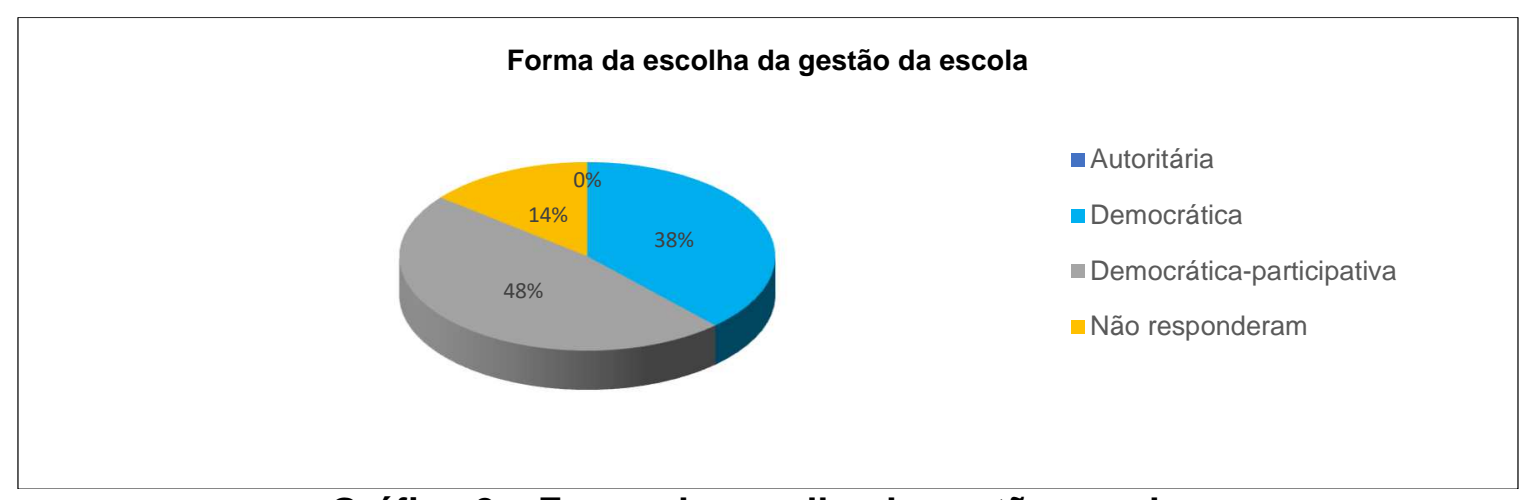

Gráfico 2 - Forma de escolha da gestão escolar.

Fonte: Dados elaborados pelas autoras a partir da pesquisa de campo (2016).

Os dados do gráfico 2 demonstram que para os sujeitos da pesquisa existe nas escolas do campo do município pesquisado, a existência de uma gestão democrática (38\%), ou ainda democrática-participativa (43\%). Entretanto, observamos que os sujeitos não compreendem que essa forma de gestão tem como pressuposto a garantia da participação de toda a comunidade escolar. Pois ao serem questionados por quem são tomadas as decisões da escola, um dado chamou atenção, uma vez que na maioria das vezes as 
decisões são tomadas pelo professor e diretor. Seguem os números: Apenas pela gestão: 0, De forma coletiva entre gestão e professores: 11 , De forma coletiva com toda a comunidade escolar: 7, Não responderam: 3

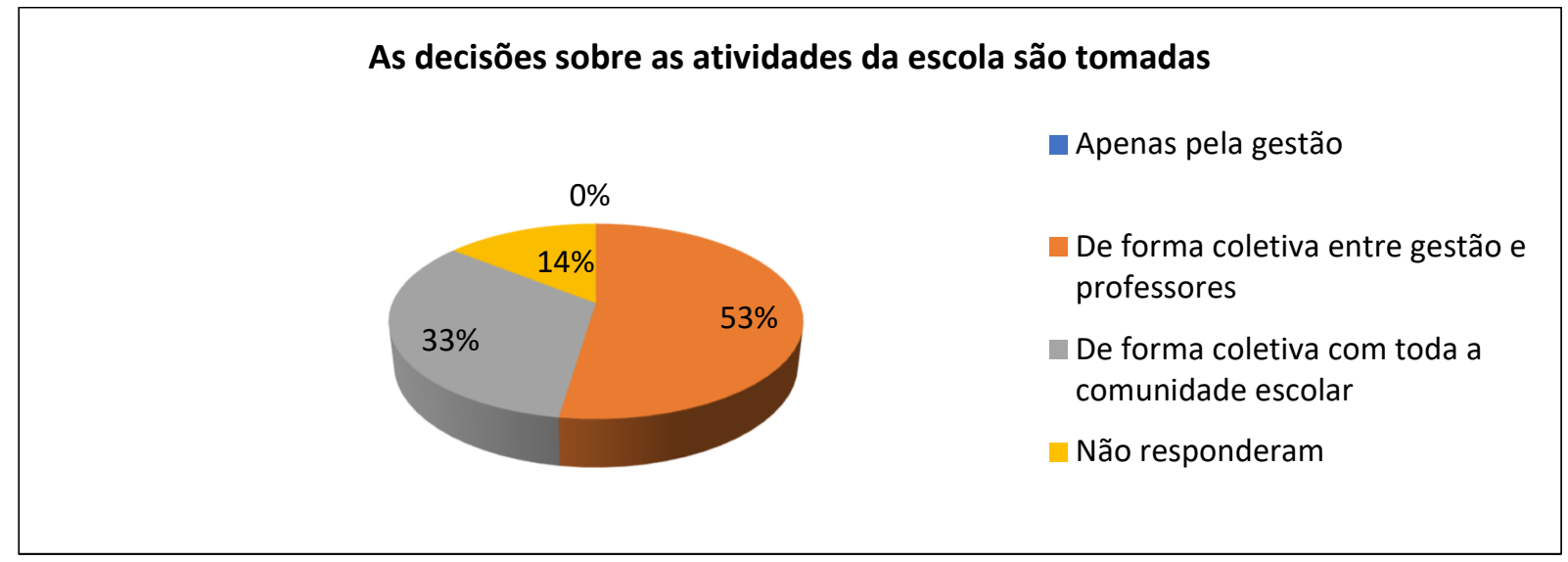

\section{Gráfico 3 - Sujeitos que tomam as decisões da escola.}

Fonte: Dados elaborados pelas autoras a partir da pesquisa de campo (2016).

O fato de alguns professores ainda retratarem a existência de gestão autoritária e de as decisões serem tomadas, na maioria dos casos, pelos professores junto com a direção (53\%), conforme demonstra o Gráfico 3, destoa de uma prática democrática, porque não inclui os alunos, pais, demais funcionários e comunidade na tomada de decisões. Percebemos nesses dados também que existe uma negligência quanto ao aspecto legal, no que se refere ao Art. 14 da LDB 9.394/96, quando afirma:

Art. 14. Os sistemas de ensino definirão as normas da gestão democrática do ensino público na educação básica, de acordo com as suas peculiaridades e conforme os seguintes princípios:

I - participação dos profissionais da educação na elaboração do projeto pedagógico da escola;

II - participação das comunidades escolar e local em conselhos escolares ou equivalentes (BRASIL, 1996).

A gestão autoritária não se dá apenas quando é utilizada a máquina burocrática do Estado para exercício do poder ou quando há abuso de autoridade administrativa de modo direto. O autoritarismo se dá também, e em especial, quando o Estado deixa de prover a escolha de recursos necessários à realização de seus objetivos (PARO, 2001).

Numa perspectiva sociocrítica, a participação é um importante instrumento de democratização da educação, a partir do momento em que todos aqueles que são afetados pelo processo educacional passam a ser reconhecidos como partes legítimas para interferir no processo de construção do projeto educacional.

Observa-se de acordo com os dados evidenciados, que a gestão escolar enfrenta as contradições sociais, por meio dos mecanismos de poder e dominação, devido ao fato de estar imersa à lógica do sistema capitalista, sendo submetida a normatização das escolas públicas e nos instrumentos de base racional-legal necessários para a legitimidade da 
educação na sociedade civil. A práxis de que trata nesse contexto é historicamente determinada e unilateral, é a práxis utilitária dos indivíduos, baseada na divisão do trabalho, na divisão da sociedade em classes e na hierarquia de posições que sobre ela se ergue (KOSIK, 1995).

Essas informações, por si só, não são capazes de fazer um levantamento preciso sobre a gestão democrática nas escolas do campo do município de Itabuna- $\mathrm{Ba}$, contudo conseguem transmitir um retrato de que há ineficiências na compreensão de gestão democrática. A gestão democrática deve ser constituída por meio da participação efetiva da comunidade escolar, pais, alunos, professores, gestores, funcionários e membros da comunidade.

\section{CONSIDERAÇÕES FINAIS}

Abordar gestão democrática na educação do campo ainda consiste em um grande desafio, pois o descaso de séculos ainda reverbera, desde a escolha de funcionários, até estrutura das escolas e questões de regulação governamental, todavia as escolas do campo são lugares de luta. Acabar com a história de descaso e de extermínio da educação do campo ainda é necessário, uma escola mais forte perpassa pelos princípios da gestão democrática, para isso, é preciso enfrentar a lógica do capital. Estimular a criação de colegiados, a participação de alunos, inserir e abrir as escolas para a comunidade.

O sentimento de pertença da escola não pode ficar restrito aos diretores e professores, mas a toda comunidade escolar que deve estar ciente de seus papéis e preocupar-se com eles. Trabalhar em prol de uma educação horizontal, não de baixo para cima.

É nítido que ainda há muito para avançar para que a gestão democrática da educação deixe de constar apenas na lei e passe a ser incorporada na prática social da escola. Ela constitui um caminho para a melhoria do ensino e da transformação social, tão necessária para melhores condições de vida, para a tomada de consciência do homem sobre o seu papel ontológico com participação ativa na construção da sociedade.

As nossas análises aqui apresentadas nos fizeram perceber que as políticas públicas educacionais brasileiras no que se refere à gestão democrático-participativas são tomadas como coadjuvantes apesar de terem importância chave para a emancipação do sujeito campesino. Para isso, nos moldes atuais, seria essencial, um trabalho conjunto entre os entes federados, bem como o planejamento coletivo necessário. Entretanto, reconhecemos que os dados aqui apresentados fazem parte dos fenômenos depreendidos das contradições presentes na sociedade capitalista, influenciada pelo mercado, que no momento atual, apresenta como alternativa a centralização e controle do Estado e regulação e controle em todo o território brasileiro. E a Educação do Campo faz parte desse contexto. 


\section{REFERÊNCIAS}

BORDENAVE, J.E. D. O que é participação. São Paulo: Brasiliense, 1994.

BRASIL. Constituição da República Federativa do Brasil. Brasília: Senado Federal, 1988. . Ministério da Educação. Resolução CNE/CEB no 1, de 3 de abril de 2002. Institui

Diretrizes Operacionais para a Educação Básica das Escolas do Campo. Diário Oficial da União, Poder Legislativo, Brasília, DF, 9 abr. 2002.

Parecer CNE/CEB nำ1/2006. Dias Letivos para a aplicação da Alternância nos Centros Familiares de Formação por Alternância. Brasília, 2006.

Decreto $n^{\circ} 7.352$ de 4 de novembro de 2010. Institui o Programa Nacional de Educação na Reforma Agrária. Brasília, 2010.

.Lei n. 9.394, de 20 de dezembro de 1996. Estabelece as diretrizes e bases da educação nacional. Diário Oficial [da] República Federativa do Brasil, Poder Legislativo, Brasília, DF, 23 dez. 1996.

CALDART, R. S. Por uma Educação do Campo: traços de uma identidade em construção. In: ARROYO, Miguel Gonzalez [et al] (orgs). Petrópolis: Vozes, 2004. p.147158.

CARNOY, M. Estado e teoria política [tradução pela equipe de tradutores do Instituto de Letras da PUC- Campinas].- 2 ed. Campinas, SP: Papirus, 1988. (10 Edição- 2004).

CHEVALIER, J. As grandes obras políticas: de Maquiavel aos nossos dias. Rio de Janeiro: Agir, $2^{\mathrm{a}}$ ed. 1982.

COUTINHO, C.N. A democracia como valor universal. In: SILVEIRA, Enio et al. Encontros com a Civilização Brasileira. Rio de Janeiro: Civilização Brasileira, 1979, p. 33-47.

ENGELS, F. Barbárie e civilazação. In: A origem da família, da propriedade privada e do Estado. Rio de Janeiro: Bertrand Brasil, 2002.

GRACINDO, R. V. Conselho Escolar e Educação do Campo. Brasília: 2006.

HORA, D. L. da. Gestão educacional democrática. Campinas, SP: Alínea, 2007.

KOSIK, K. Dialética do concreto. 6. ed. Paz e Terra: Paz e Terra, 1995.

MÉSZÁROS, I. A educação para além do capital. Tradução de Isa Tavares. São Paulo: Boitempo, 2005.

, I. Para Além do capital. São Paulo: Boitempo, 2004.

MINAYO, M. C. de S. (org.). Pesquisa Social. Teoria, método e criatividade. 18 ed. Petrópolis: Vozes, 2001.

PARO, V. H. Administração escolar: introdução crítica. 17 ed. São Paulo: Cortez, 2012.

Gestão Democrática da escola pública. 3aㅗ ed .São Paulo: Ática. 2001.

SANTOS, A. R. dos. Ocupar, Resistir e Produzir, também na educação! O MST e a Burocracia Estatal: negação e consenso. Jundiaí, Paco editorial. 2014. 
SANTOS, A. R. dos; CARDOSO, E. A. M; OLIVEIRA, N. B. Os impactos do PAR nos municípios de Vitória da Conquista, Ilhéus e Itabuna. Revista Práxis Educacional, Vitória da Conquista, v. 13, n. 26, p. 110-139, set./dez. 2017.

WOOD, E.M. O que é (anti) capitalismo? Revista Crítica Marxista. N. 17, p. 37-50, 2006. 